\title{
DISTRIBUTION OF SCATTER IN NEW ZEALAND ACCELEROGRAPH DATA
}

\author{
J.B. Berrill*
}

\begin{abstract}
This study examines the currently available set of 22 New Zealand strong motion accelerograms to determine values of the scatter parameters for use in correcting for attenuation uncertainty in seismic hazard analyses. In particular, scatter of observed acceleration response spectral ordinates about mean values predicted by the attenuation law of Katayama, Iwaski and seaki is investigated. It is found that to a high level of statistical significance, the observed spectral ordinates are lognormally distributed about the predicted values. For the data as a whole, lumping samples from the nine natural periods studied, the standard deviation of the logarithmic residuals is $\sigma_{1}=0.25$. However, values of $\sigma$. for distinct natural periods are quite scattered in an apparentIy random manner, suggesting that the set of accelerograms is not large enough to yield stable results on a period-by-period basis. Eurthermore, since there is no recording of severely damaging ground motions amongst the accelarograms, it is not clear that the value of $\sigma_{10}=0.25$ is characteristic of hazardous ground motions in New zealand, especially when it is compared with the value of 0.3 obtained from the more extensive Japanese data set. For immediate practical purposes, it is proposed that scatter parameters obtained from a combined. New Zealand-Japanese data set be used. These records taken together yield values of $0_{10}$ increasing from 0.28 at a natural period of 0.1 s to 0.32 at 1.0 seconds and above. Employing these values rather than $\sigma_{10}=0.25$, results in a 20 percent increase in the peak of the 150-year uniform risk spectrum for Wellington.
\end{abstract}

INTRODUCTION

During the past five or six years a number of studies have been made of seismic hazard in New Zealand using probabilistic seismic hazard analysis techniques ${ }^{-4}$. These studies have been empioyed to derive the uniform risk response spectra used in the draft NZNSEF code "Seismic Design of Bridges" and, with some refinement, are being used to develop spectra for the forthcoming revision of the $\mathrm{NZ}$ loadings code for buildings, NZS 4203. Of the various sources of uncertainty in the estimation of seismic hazard, one of the most critical is uncertainty in the attentuation law ${ }^{-9}$. The computed seismic hazard is highly sensitive to the degree of randomness in attenuation. Therefore it is important that the random component of the attenuation law be quantified as precisely as possible according to the characteristics of the region under consideration. If the degree of dispersion of attenuation about the mean attenuation law is ignored or underestimated, then the hazard may be seriously underestimated. on the other hand, comparatively small amounts of conservatism in the dispersion parameters may result in large increases in computed hazard. precise estimation of the appropriate degree of randomness is especially difficult for New Zealand because of the scarcity of strong motion data.

* Department of Civil Engineering

University of Canterbury, Christchurch,

New Zealand

BULLETIN OF THE NEW ZEALAND NATIONAL SOCIETY FOR EARTHOUAKE ENGINEERING, Vol 18, No 2, JUNE 1985
The aim of this article is to examine the set of New Zealand strong motion accelerograms in order to find appropriate values of the attenuation uncertainty or randomness parameters with respect to the attenuation law of Katayama, Iwasaki and seakill used in current hazard analyses in this country. The companion article 10 in this issue outlines the hazard analysis procedure, and reviews recent work in the application of hazard analyses to New zealand and in the formulation of seismic design loads. The reader unfamiliar with seismic hazard analyses is referred to that article, especially to the discussion of attenuation uncertainty.

The point of departure of the present article is equation (11) of the companion article, namely:

$$
i=z i(m, r)
$$

in which $m$ denotes earthquake magnitude, $r$ distance and $\hat{i}$ denotes the (random) intensity of motion produced at a site at a distance $r$ by an earthquake of magnitude $m$. The function $i(m, r)$ denotes the mean attenuation law; $z$ is a random variable describing randomness in attenuation. Note that equation (1) models the earthquake source, through its dependence on $m$, as well as the attenuation of seismic waves with distance. 


\begin{tabular}{|c|c|c|c|c|c|c|}
\hline No & Accelerograph site & Earthquake & Date & Magnitude & $\begin{array}{c}\text { Epicentral } \\
\text { Distance } \\
\mathrm{km}\end{array}$ & $\begin{array}{l}\text { Ground } \\
\text { Conditjon }\end{array}$ \\
\hline 1 & $\begin{array}{l}\text { Westport Telephone } \\
\text { Exchange }\end{array}$ & $\begin{array}{l}\text { Inangahua } \\
\text { aftershock }\end{array}$ & $24 / 05 / 68$ & 6.0 & 35 & II \\
\hline 2 & $\begin{array}{l}\text { Westport Telephone } \\
\text { Exchange }\end{array}$ & $\begin{array}{l}\text { Inangahua } \\
\text { aftershock }\end{array}$ & $25 / 05 / 68$ & 5.5 & 25 & II \\
\hline 3 & $\begin{array}{l}\text { Westport Telephone } \\
\text { Exchange }\end{array}$ & $\begin{array}{l}\text { Inangahua } \\
\text { aftershock }\end{array}$ & $14 / 06 / 68$ & 5.5 & 30 & II \\
\hline 4 & $\begin{array}{l}\text { Te Anau Fire } \\
\text { Station }\end{array}$ & Milford Sound & $04 / 05 / 76$ & 7.0 & 84 & III \\
\hline 5 & Milford Sound Hotel & Milford Sound & $04 / 05 / 76$ & 7.0 & 37 & I.II \\
\hline 6 & $\begin{array}{l}\text { Wanaka National Park } \\
\text { Headquarters }\end{array}$ & Milford Sound & $04 / 05 / 76$ & 7.0 & 134 & III \\
\hline 7 & $\begin{array}{l}\text { Vogel Building } \\
\text { Wellington (Remote) }\end{array}$ & Cook strait & $18 / 01 / 77$ & 6.2 & 64 & II \\
\hline 8 & $\begin{array}{l}\text { Vogel Building } \\
\text { Well'ton (Basement) }\end{array}$ & Cook Strait & $18 / 01 / 77$ & 6.2 & 64 & II \\
\hline 9 & $\begin{array}{l}\text { Wellington Airport } \\
\text { Fire Station }\end{array}$ & Cook strait & $18 / 01 / 77$ & 6.2 & 63 & II \\
\hline 10 & $\begin{array}{l}\text { Gray and Elliot Bdg } \\
\text { Bute St, Wellington }\end{array}$ & Cook Strait & $10 / 01 / 77$ & 6.2 & 64 & III \\
\hline 11 & $\begin{array}{l}\text { Central Libraxy } \\
\text { Wellington }\end{array}$ & Cook Strait & $10 / 01 / 77$ & 6.2 & 65 & IV \\
\hline 12 & $\begin{array}{l}\text { ANZ Bank, Cuba st } \\
\text { Wel Iington }\end{array}$ & Cook Strait & $10 / 01 / 77$ & 6.2 & 65 & III \\
\hline 13 & $\begin{array}{l}\text { Gear Meat Co. } \\
\text { Petone }\end{array}$ & Cook strait & $10 / 01 / 77$ & 6.2 & 76 & III \\
\hline 14 & $\begin{array}{l}\text { PEI Bdg, DSIR } \\
\text { Lower Hutt }\end{array}$ & Cook strait & $10 / 01 / 77$ & 6.2 & 77 & III \\
\hline 15 & $\begin{array}{l}\text { PEL Bdg, DSIR } \\
\text { Lower Hutt }\end{array}$ & Seddon & $23 / 04 / 66$ & 6.0 & 63 & III \\
\hline 16 & $\begin{array}{l}\text { Napier Telephone } \\
\text { Exchange, Marewa }\end{array}$ & Napier & $05 / 10 / 80$ & 5.6 & 24 & IV \\
\hline 17 & $\begin{array}{l}\text { Napier Telephone } \\
\text { Exchange, Marewa }\end{array}$ & ? & $02 / 09 / 82$ & 5.4 & 35 & IV \\
\hline 18 & Ooanui Gas Plant & ? & $16 / 04 / 83$ & 5.5 & 42 & IV \\
\hline 19 & Ooanui Gas Plant & ? & $16 / 04 / 83$ & 5.2 & 39 & IV \\
\hline 20 & $\begin{array}{l}\text { Haywards NZE } \\
\text { Distribution Station }\end{array}$ & Palliser Bay & $01 / 11 / 68$ & 5.5 & 50 & I \\
\hline 21 & $\begin{array}{l}\text { Chief Post office } \\
\text { Gisborne (Ground } \\
\text { floor) }\end{array}$ & Gisborne & $03 / 03 / 82$ & 5.1 & 25 & IV \\
\hline 22 & $\begin{array}{l}\text { Chief Post Office } \\
\text { Gisborne (car park) }\end{array}$ & Gisborne & $03 / 03 / 82$ & 5.1 & 25 & IV \\
\hline
\end{tabular}

Table 1. Ground-level recordings from crustal earthquakes in New Zealand. 
our problem is to determine the distribution of $\mathrm{Z}$ for New Zealand strong motion, given that the mean attenuation $i(m, r)$ is represented by the model of Katayama, Iwasaki and Seakill. At the time of writing 22 New Zealand strong motion accelerograms were available, and observed values of $Z$ derived from them form the basic data set. First, the common assumption that $Z$ is lognormally distributed is examined, and then means and standard deviations are estimated.

NEW ZEALAND STRONG MOTION ACCELEROGRAMS

Twenty-two strong motion accelerograms recorded by the Engineering Seismology section of the New Zealand DSIR at ground level, on basement floors or in the free field form the basis for the study described below. The accelerograms are listed in Table 1 , together with seismological and site information. Their geographical distribution is shown in Figure 1. The 22 accelerograms come from 11 earthquakes, three of which were aftershocks. Records 1 to 16 formed the set studied earlier by Mulholland ${ }^{3}$; numbers 17 to 22 have been processed since Mulholland's study.

\section{NEW ZEALAND}

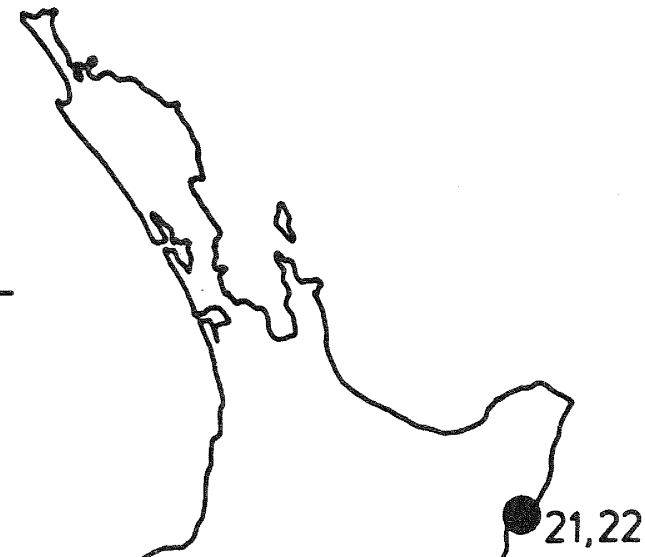

18,19

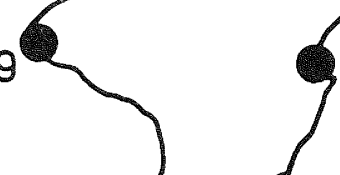

16,17

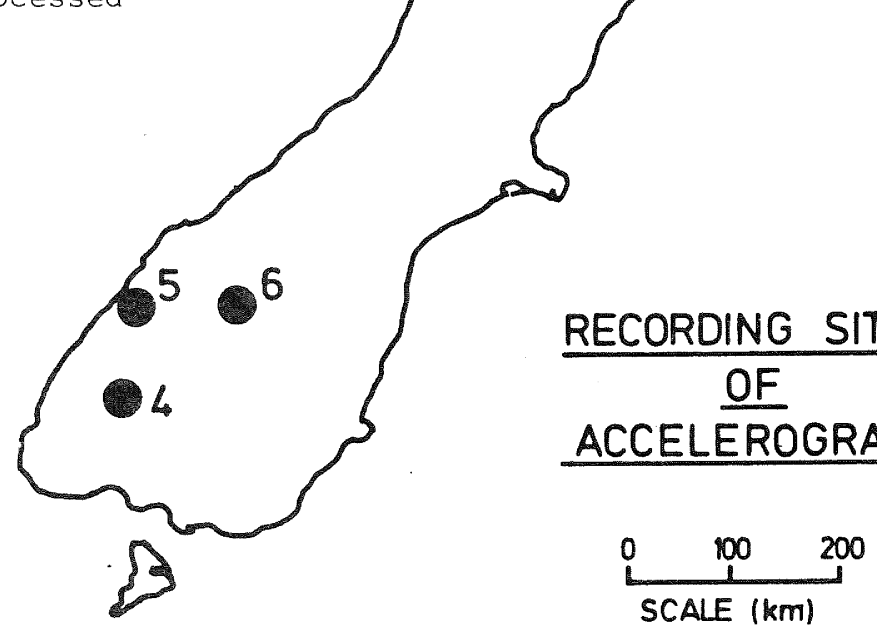

Figure 1. Recording sites of the 22 accelerograms of the data set

The ground conditions at the accelerograph sites are classified according to the four-step Japanese system employed by Katayama et al. II, using borelog data where possible. In some cases the classifications assigned by Mulholland have been revised (resulting in a small reduction in scatter). Table 2, from Ohashi et al.12, gives details of the Japanese site classification system, and has been used in the reclassification of the New Zealand sites. 
Table 2. Japanese system for classifying site ground conditions (from ref. 12)

\begin{tabular}{|c|c|}
\hline Group & Definitions $^{1}$ ) \\
\hline I & $\begin{array}{l}\text { (1) Ground of the Tertiary era } \\
\text { or older (defined as bed } \\
\text { rock hereafter) } \\
\text { (2) Diluvial layer }{ }^{2} \text { with } \\
\text { depth less than } 10 \text { metres } \\
\text { above bedrock }\end{array}$ \\
\hline II & $\begin{array}{l}\text { (1) Diluvial layer }{ }^{2} \text { with } \\
\text { depth greater than } 10 \text { metres } \\
\text { above bedrock } \\
\text { (2) Alluvial layer }{ }^{3} \text { with } \\
\text { depth less than } 10 \text { metres } \\
\text { above bedrock }\end{array}$ \\
\hline I I I & $\begin{array}{l}\text { Alluvial layer }{ }^{3)} \text { with depth } \\
\text { less than } 25 \text { metres, which has } \\
\text { soft layer } 4 \text { with depth less } \\
\text { than } 5 \text { metres }\end{array}$ \\
\hline IV & Other than the above \\
\hline
\end{tabular}

(Notes) 1) Since these definitions are not very comprehensive, the classification of ground conditions shall be made with adequate consideration of the [bridge] site.

Depth of layer indicated here shall be measured from the actual ground surface.

2) Diluvial layer implies a dense alluvial layer such as a dense sandy layer, gravel layer or cobble layer.

3) Alluvial layer implies a new sedimentary layer made by a landslide.

4) Soft layer is defined in Section 3.7 [of reference 13] "Soil Layer Whose Bearing Capacities are Neglected in Earthquake Resistant Design".

SCATTER ABOUT THE ATTENUATION MODEL OF KATAYAMA ET AL.

A set of observed values of $Z$ was obtained by first computing the absolute acceleration response spectrum with five percent damping for each of the 22 accelerograms. These spectra were then sampled at nine natural periods $T_{j}$ in the band $0.10 \mathrm{~s}$ to $2.0 \mathrm{~s}$ to obtain a set of observed spectral ordinates $\hat{\mathrm{S}}_{i j}(i=$ $1,22 ; j=1,9)$. Values of $z^{j}$ were computed by dividing the observed spectral ordinates $\hat{\mathrm{S}}_{i j}$ by the corresponding values $s_{i j}{ }_{i j}$ predicted by the Katayama model. Thatjis,

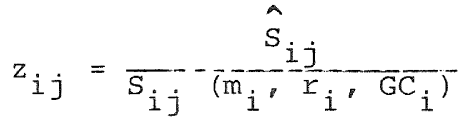

where $m_{i}$, $r_{i}$, $G_{i}$ are the magnitude, épicentrial distance and ground condition of the ith accelerogram, taken from Table 1 . Noting that the various influences on strength of shaking (such as the earthquake source mechanism, directivity effects, properties of the propagation path and local site conditions) are multiplicative, and appealing to the central limit theorem of probability theory, it is expected that $Z$ will be lognormally distributed. Thus the set of logarithmic residuals

$$
x_{i j}=\log _{10} z_{i j}
$$

were taken as the basic data set for this study. These residuals are listed in Table 3, together with means and standard deviations of various subsets.

First, the set of logarithmic residuals is plotted in Figure 2 against the independent variables of the Katayama model to check for any obvious trends. There does not appear to be any gross trend with respect to distance or magnitude, although in both cases there appears to be a slight overall decrease in the mean value of $x$ with both increasing distance and magnitude. However the trend is slight, especially in view of the amount of scatter overall, and is due principally in both figures to data from a single earthquake, the 1976, $\mathrm{M}=7$ Milford sound earthquake. As for the amount of scatter, there does not appear to be any obvious correlation with either distance or magnitude. In the plot of $X$ versus ground condition, the average value of $X$ appears to be smaller for Class 3 than for the other categories, although again the amounts of scatter seem similar in all cases. The other unusual group in the ground condition plot is that of $\mathrm{GC}=1$. However, with only one recording in this category (Haywards, 1968), little general significance can be attached to it. In the plot of $X$ versus $T$ there is a small decrease in the mean value of $x$ with increasing period (as observed by Mulholland ${ }^{4}$, but here again, the amount of scatter appears to be independent of T.

To examine the distribution of the residuals in more detail, and in particular to test the assumption that $Z$ is lognormally distributed, histograms of observed values of $X$ are plotted in Figure 3 for the periods $T=0.1,0.5$, 1.0 and $2.0 \mathrm{~s}$. Corresponding normal distributions are also shown. There are not enough data in these plots to apply the Chi-squared goodness-of-fit test at the individual periods (a minimum of five samples per category is required ${ }^{14}$. However, the Kolmogorov-Smirnov (K $S$ ) test (see, for example Ang and Tang ${ }^{I}$ ) may be employed. Under this test, the worst case occurs in the $\mathrm{T}=1.0 \mathrm{~s}$ data, for which the cumulative distribution is plotted in Figure 4. The greatest 


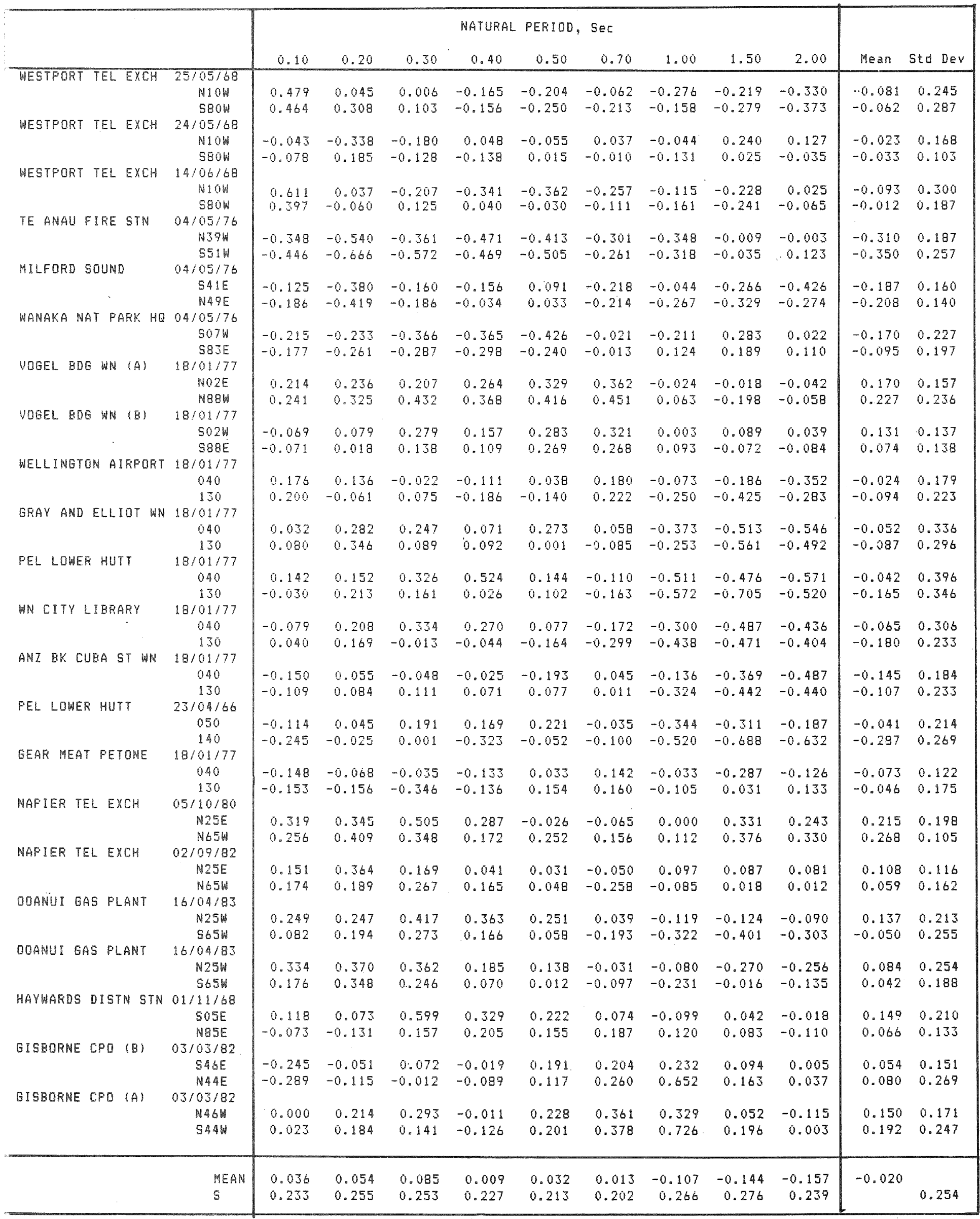



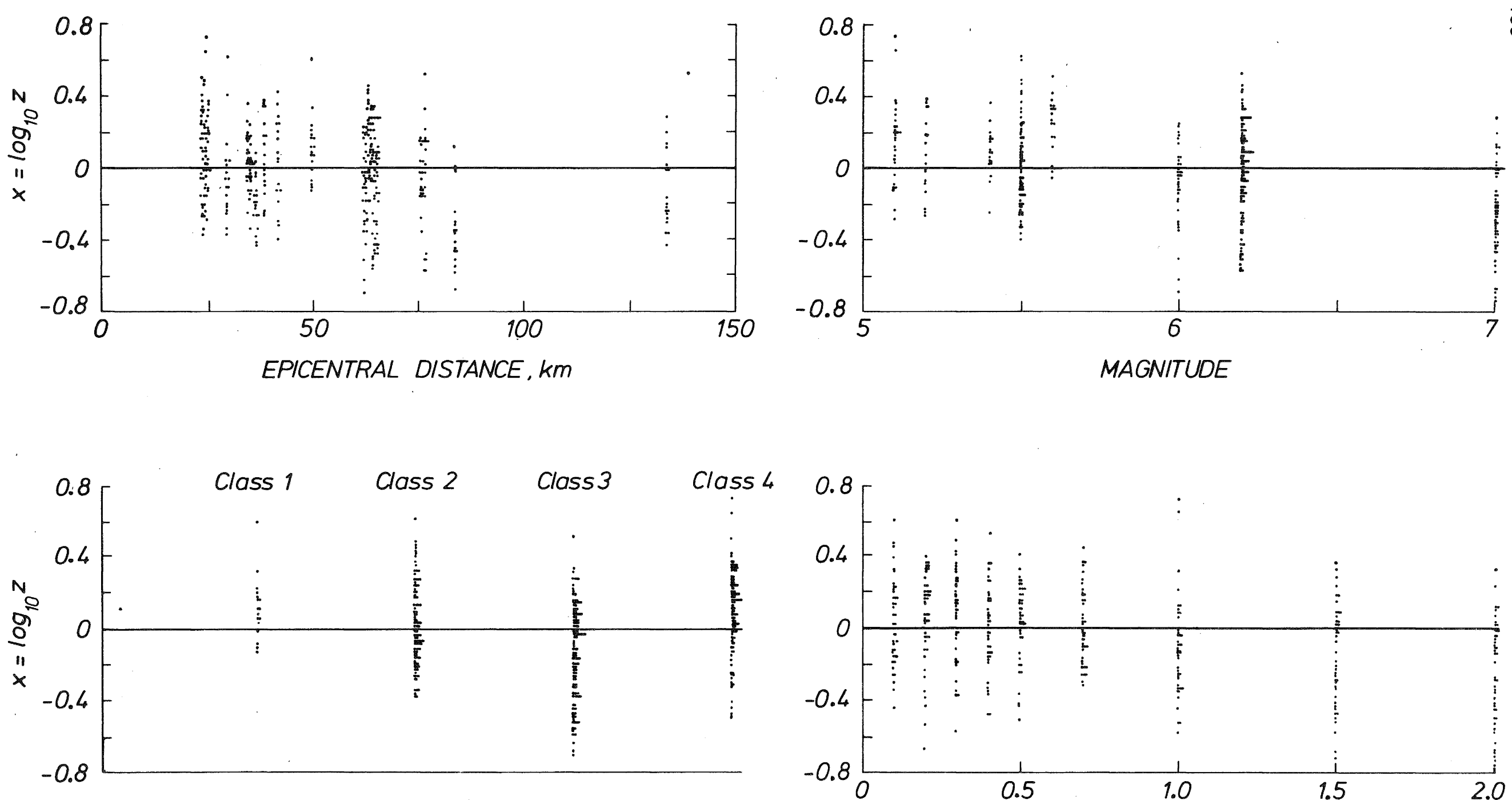

GROUND CONDITION

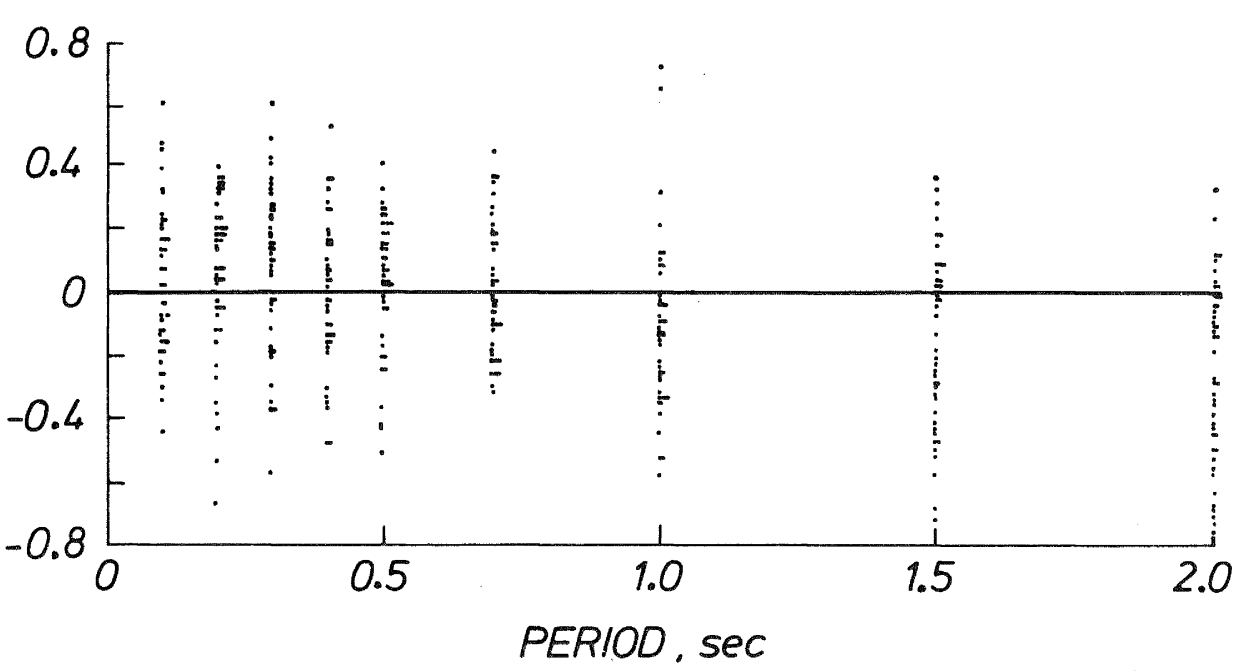

Figure 2. Plots of the logarithmic residuals versus the parameters of the Katayama attenuation law. 
deviation, $D$, of the observed cumulative distribution from the fitted lognormal function is $D_{\text {ma }}=0.112$, well within the critical malues of 0.20 and 0.16 at five percent and 20 percent confidence levels respectively, supporting the assumption that $Z$ is lognormally distributed. Values of D found for other sampling periods arex shown in Table 4. Also shown in the table are values of $D_{\text {assuming }} \mathrm{z}$ is normally distributed. $\mathrm{As}^{\mathrm{S}}$ expected, it is seen that at most periods the lognormal assumption gives a markedly better fit. The overall fit is tested by lumping all nine period categories together. In this case $D=0.0345$ when $Z$ is assumed to be lognormal, and $D_{\text {max }}=0.109$ assuming $\mathrm{z}$ is normally distributed. Clearly the assumption of lognormality gives a much better fit overall.
When data at the four periods studied in Figure 3 are lumped together, the histogram shown in Figure 5 results. Clearly, these data fit the lognormal distribution well (suggesting that the samples at individual natural periods are too small). Lumping data for $x>0.35$ and $\mathrm{x}<-0.45$ to satisfy the $\mathrm{n}>5$ criterion, results in a chi-squared value of 4.80. This compares with a critical value of 15.5 at the five percent level. again strongly supporting the lognormal assumption.

Table 4. Values of $D_{\text {max }}$ for the Kolmogorov-Smirnov test under the assumptions that $\mathrm{z}$ is normally and lognormally distributed

\begin{tabular}{|l|l|l|l|l|l|l|l|l|l|}
\hline Period, T sec & 0.1 & 0.2 & 0.3 & 0.4 & 0.5 & 0.7 & 1.0 & 1.5 & 2.0 \\
\hline $\begin{array}{l}\text { Dax́m } \\
\mathrm{Z}_{\text {Iónormal }} \\
\mathrm{D}_{\text {max́rmal }}\end{array}$ & 0.106 & 0.087 & 0.070 & 0.048 & 0.101 & 0.091 & 0.112 & 0.085 & 0.105 \\
\hline
\end{tabular}
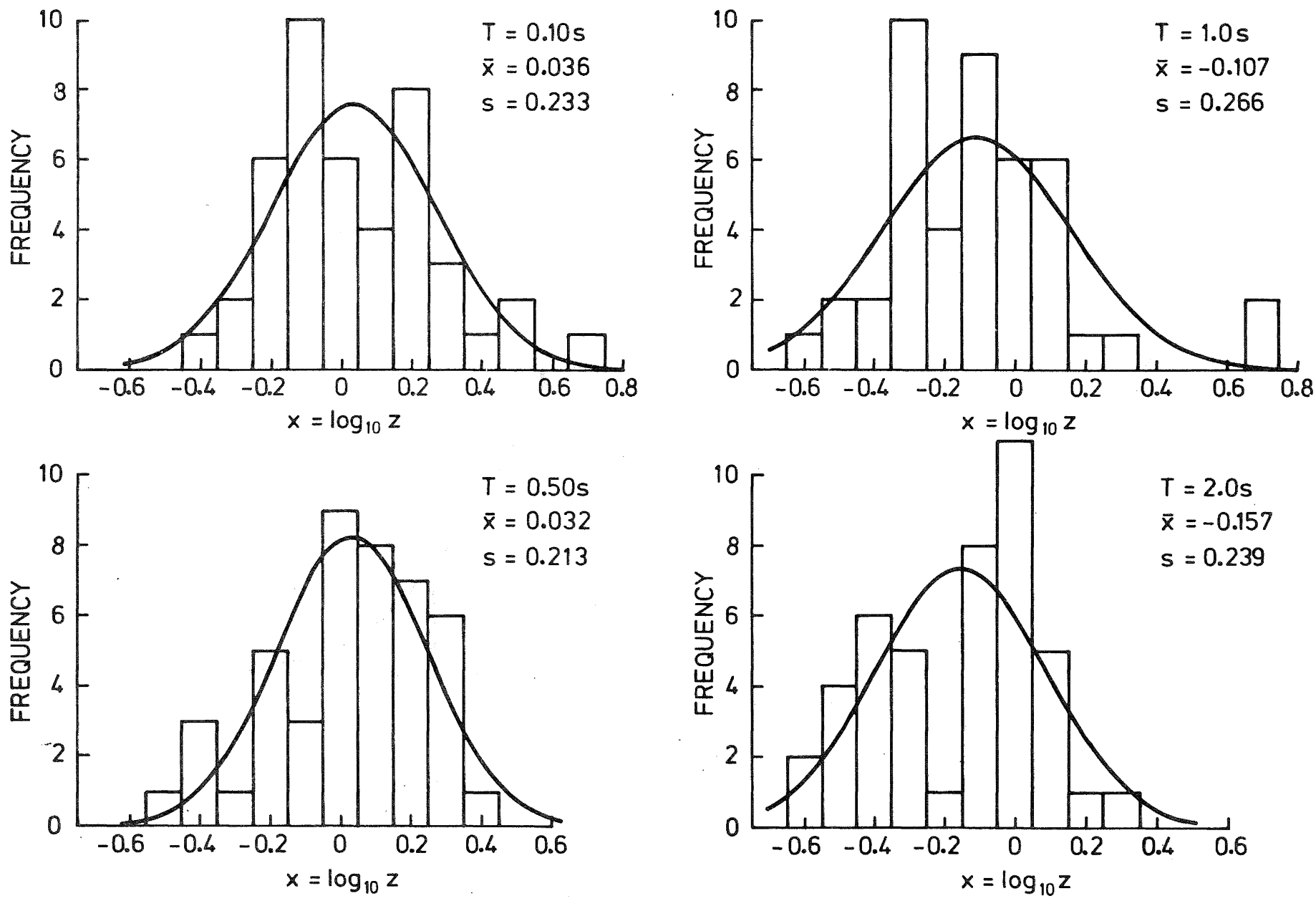

Eigure 3. Histograms of the log residuals at natural periods $T=0.1,0.5$, 1.0 and 2.0 seconds 


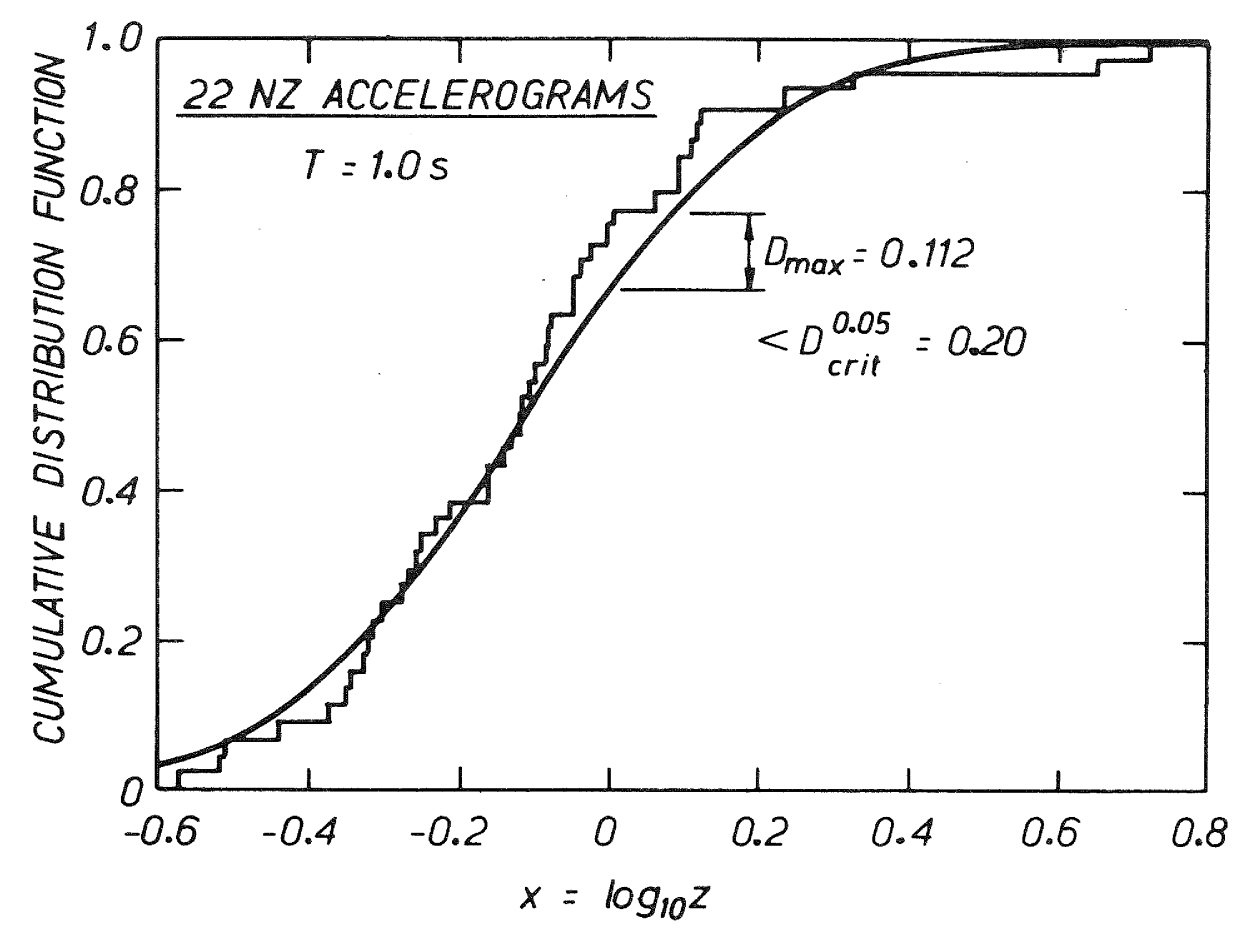

Figure 4. Observed versus lognormal cumulative distributions for the case of worst fit, $T=1.0 \mathrm{~s}$



Figure 5. Histogram of logarithmic residuals from samples at $\mathrm{T}=0.1,0.5$, 1.5 and 2.0 , lumped together 
Accepting that $\mathrm{Z}$ is lognormally distributed, the problem becomes that of finding suitable values of the mean $\mu$ and standard deviation $\sigma$ of $\mathrm{x}=$ $\log _{10} z$ to describe the distribution. In this article we shall focus principally on the determination of $\sigma_{10} ;$ the problem of appropriate values $8^{f}$ the mean has been addressed by McVerry ${ }^{19}$ in revising the Katayama law.

The principal question in determining an appropriate value of standard deviation $\sigma_{10}$ to use in hazard analyses for New ${ }^{10}$ zealand, is whether or not the sample of 22 accelerograms is representative of New Zealand ground motion. From Figure 1 it is seen that the recording sites are fairly well distributed throughout the main seismic region, if somewhat clustered locally. Given a larger set, it would perhaps be prudent to reduce the number of records from the wellington region. On the other hand, since this is where the greatest risk lies, then perhaps the weighting towards wellington is appropriate.

The other variables entering the hazard analysis are magnitude, epicentral distance and ground condition. These are plotted for our 22 accelerograms in Figure 6. Here it is evident that the set of accelerograms is far from complete. For example, except for the single Milford Sound record there is no earthquake with magnitude greater than six recorded at less than $60 \mathrm{~km}$ from its epicentre. It would be difficult to argue that these records represent damaging ground motions, and in fact damage at the recording sites was not great during any of the earthquakes. Nevertheless, we must make do with what we have, and it is certainly instructive to examine the New Zealand data for trends and for consistency, even if the study does not yield reliable working values of the scatter parameters.

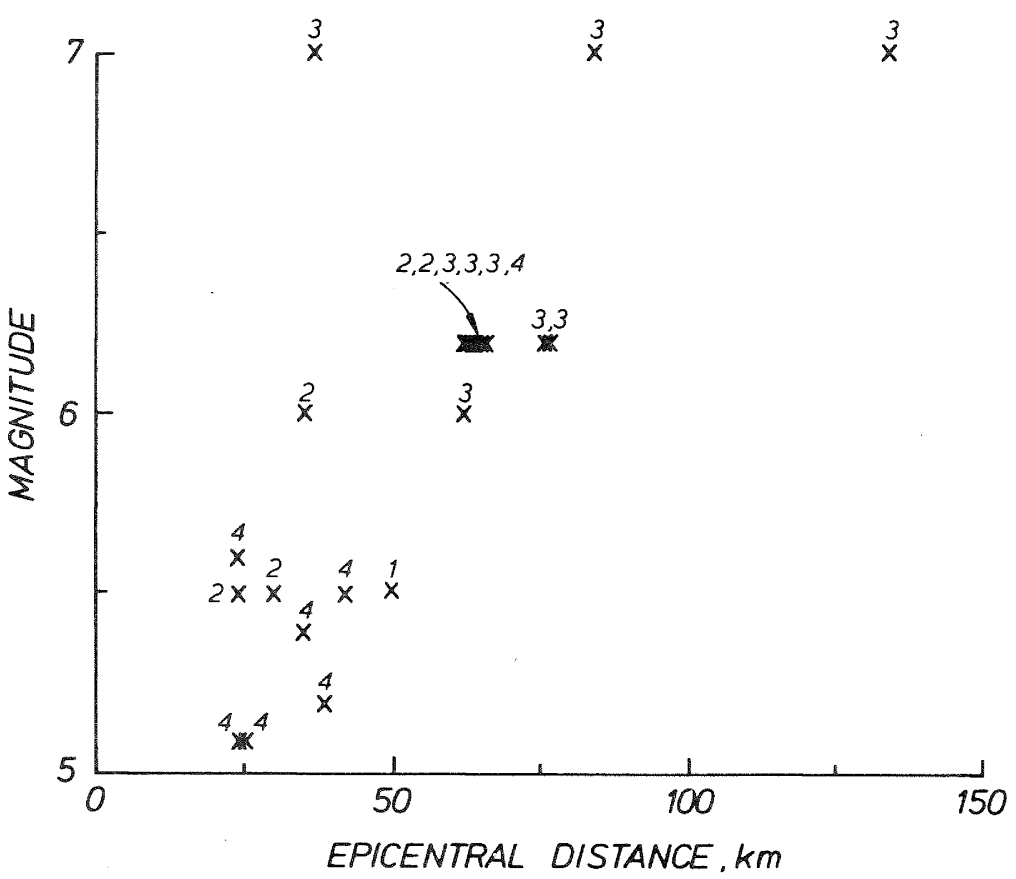

Figure 6. Magnitudes and distances of the 22 New Zealand accelerograms. Superscript numbers denote recording site ground conditions. period-by-period, taken from Table 3, are plotted in Figure 7. The individual values oscillate about the value of $\sigma_{10}=0.254$ for the data as a whole. There is a slight trend of increasing $\sigma_{10}$ with natural period, as observed by Trifunac et $a l$. 16 and 17 by McGuire in US data, and Mitchell 17 in Japanese Japanese data. However, the trend is small compared with the variation between samples. The significance of the variations from period to period may be measured using the homogeneity of variance test ${ }^{18}$. Here

$\mathrm{F}_{\text {max }}=\frac{\text { largest variance }}{\text { smaliest variance }}=\left(\frac{0.276}{0.272}\right)^{2}=1.87$

This is less than the critical value of 2.65 at the five percent significance level. Hence the variations seen here are not necessarily significant, and the true value of standard deviation may well be invariant with respect to natural period.

A further test on the homogeneity of the data set may be made by dividing it randomly into two sets of 11 accelerograms. Standard deviations for these are given in Table 5. It can be seen the patterns of variation are not the same, suggesting further that the variations are due to the small size of the data set rather than true physical phenomena. This may be demonstrated more formally using the E-statistic. At three of the nine sampling periods a test that the two sets $A$ and $B$ are drawn from the same population fails, indicating that the samples are not representative. Note, however, that the estimates of 0.256 and 0.253 for the whole subsets, lumping the periods, are close to each other and to the value of 0.254 for the entire set (comprising $22 \times 2 \times 9=396$, values of $X)$. Again the $F$-statistic may be employed to support the assumption $3 x$ 


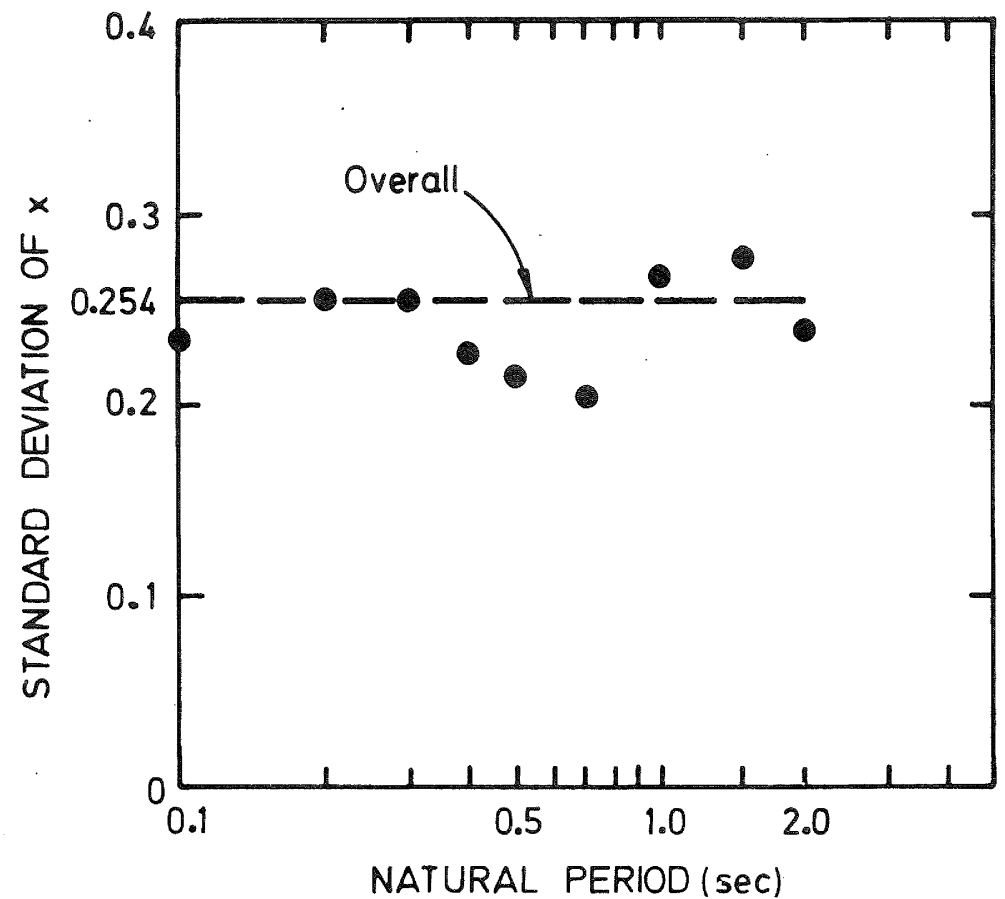

Figure 7. Standard deviations of the logarithmic residuals

that sets A and B each taken as a whole are apparently drawn from the same population and that their sampling is satisfactory.

Table 5. Standard deviations of subsets of New Zealand data formed by randomly selecting 11 accelerograms for set $A$

\begin{tabular}{|l|lllllllllll|}
\hline \multirow{2}{*}{ Data Set } & \multicolumn{7}{|c|}{ Natural Period, } \\
\cline { 2 - 9 } & 0.10 & 0.20 & 0.30 & 0.40 & 0.50 & 0.70 & 1.0 & 1.5 & 2.0 & Al1 \\
\hline A $\quad(11$ accelgms $)$ & 0.198 & 0.266 & 0.281 & 0.263 & 0.252 & 0.220 & 0.322 & 0.257 & 0.199 & 0.256 \\
B (11 accelgms $)$ & 0.242 & 0.231 & 0.211 & 0.184 & 0.169 & 0.134 & 0.175 & 0.282 & 0.262 & 0.253 \\
All 22 accelgms & 0.233 & 0.255 & 0.255 & 0.227 & 0.213 & 0.202 & 0.266 & 0.276 & 0.239 & 0.254 \\
\hline
\end{tabular}

Thus it appears that our data set is not adequate to resolve variations in standard deviation between natural periods should such variation actually exist. But it does provide an adequate sampling of small magnitude or distant New Zealand earthquakes to determine the overall value of $\sigma=$ 0.254 for these sorts of events. However, it is not demonstrated that this subset of earthquakes is representative of New zealand earthquakes as a whole.
Turning now to consideration of mean values of $x$, it is seen from the values near the bottom of Table 3 that at short periods the Katayama attenuation model has on the average underestimated the observed spectral amplitudes, most notably by 22 percent at $T=0.3 \mathrm{~s}$. At long periods the model overestimates the data by up to 30 percent at $T=2.0 \mathrm{~s}$, confirming the earlier impression given by Figure 2. While these results may justify strengthening the model at short periods, the average values at long periods may be less reliable because of the lack of large magnitude earthquakes in the data set. 


\section{CHOICE OF $\quad$ O 10 FOR HAZARD ANALYSIS}

Since the present New Zealand data set is lacking in large earthquakes and close-in recordings, it is not clear that the value of $\sigma=0.254$ is representative of all future New Zealand strong motion, especially for more damaging earthquakes. These misgivings are reinforced by comparing this value with those obtained elsewhere. Table 6 lists standard deviations estimated from other data sets. Only McGuire's values ${ }^{7}$ are comparable to the New Zealand ones. However these were obtained from a small set of Western United states earthquakes that is probably more homogeneous than can be expected for New Zealand. On the other hand, one would expect Trifunac and Anderson's datal6, coming from a broader and therefore more varied selection of earthquakes, to ge more scattered. Mitchell's values ${ }^{19}$ shown in Table 6 were obtained from a study of the 277 accelerogram components of the Japanese data set of Katayama, Iwasaki and seakil from which the attenuation model was derived. Since the tectonic regime and site conditions of Japan are generally similar to those of New Zealand, it is probable that the distribution of scatter in the Japanese data roughiy represents New Zealand conditions. The smaller values from the New zealand data may be due to the small size of the data set, with the full range of possible conditions not covered.
As more records are obtained, more reliable estimates for New Zealand conditions will be possible. However, values of the scatter parameters are required now for hazard analyses. To overcome this difficulty, it is proposed that we lump the two sets of strong motion data, the New Zealand and Japanese sets, and take our working values from the combined set. In this way we are giving some weight to the New Zealand data, but at the same time recognising the greater coverage of the Japanese recordings and the general geologic similarities of the two countries. Combining the two data sets yields the values of $\sigma_{10}$ shown in the bottom line of Table 6. These values are plotted in Figure 8 , together with suggested values of $\sigma$ for use in hazard analyses. They increase logarithmically with period from 0.1 to 1 sec, and are constant at $\sigma_{10}=0.32$ for $\mathrm{T}>1.0 \mathrm{~s}$.

To assess the effect of the results of a typical hazard analysis, uniform risk acceleration response spectra were computed for a Wellington site using first the value of $\sigma{ }=$ 0.254 indicated by the New Zealand data alone and second the recommended $\sigma$ of 0.28 increasing to 0.32 . The results are shown in normalized form in Figure 9. As expected, the difference is more marked at longer periods where the recommended values of $\sigma$ are greater. The peak of the spectrum, which occurs at $\mathrm{T}=0.2 \mathrm{~s}$, is increased by just under 20 percent by the adoption of values recommended above.

Table 6. Comparison of $\sigma$ estimates with those obtained elsewhere

\begin{tabular}{|c|c|c|c|c|c|c|c|}
\hline Period, sec & 0.10 & 0.20 & 0.3 & 0.5 & 1.0 & 2.0 & 4.0 \\
\hline This study & 0.233 & 0.255 & 0.253 & 0.213 & 0.266 & 0.239 & - \\
\hline $\begin{array}{l}\text { McGuire } \\
\text { (Western US) }\end{array}$ & 0.258 & 0.233 & 0.227 & 0.238 & 0.275 & 0.346 & 0.408 \\
\hline $\begin{array}{l}\text { Trifunac } 16 \text { nd } \\
\text { Anderson } \\
\text { (Western US) }\end{array}$ & 0.36 & - & 0.37 & 0.38 & 0.41 & 0.45 & 0.50 \\
\hline $\begin{array}{l}\text { Mitche11 } 17 \\
\text { (Japanese data) }\end{array}$ & 0.288 & - & - & 0.320 & 0.325 & - & 0.303 \\
\hline $\begin{array}{l}\text { New Zealand and } \\
\text { Japanese data }\end{array}$ & 0.281 & - & - & 0.310 & 0.319 & - & 0.303 \\
\hline
\end{tabular}




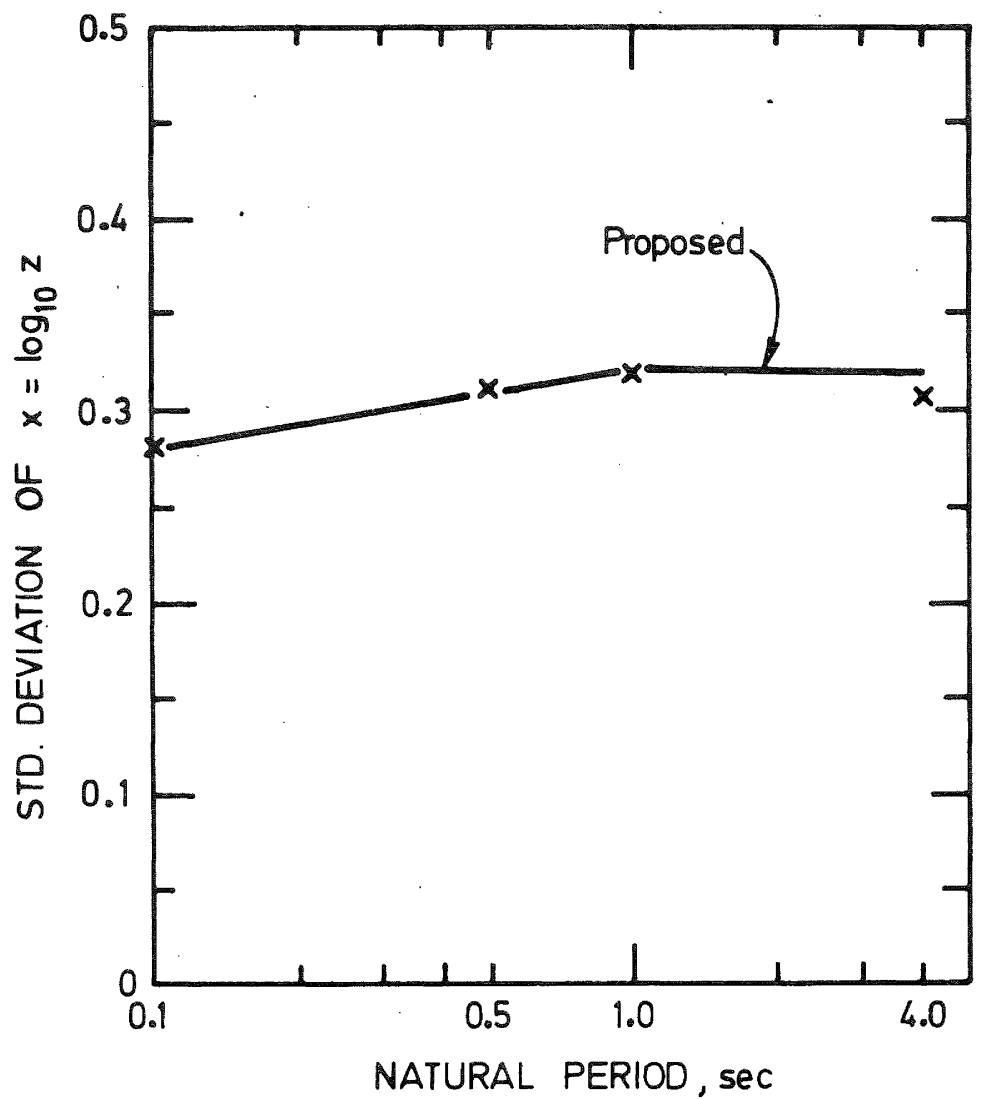

Figure 8. Standard deviations from the combined Japanese-New Zealand data set. Solid line shows interim values of $\sigma_{10}$ proposed for use in hazard analyses.

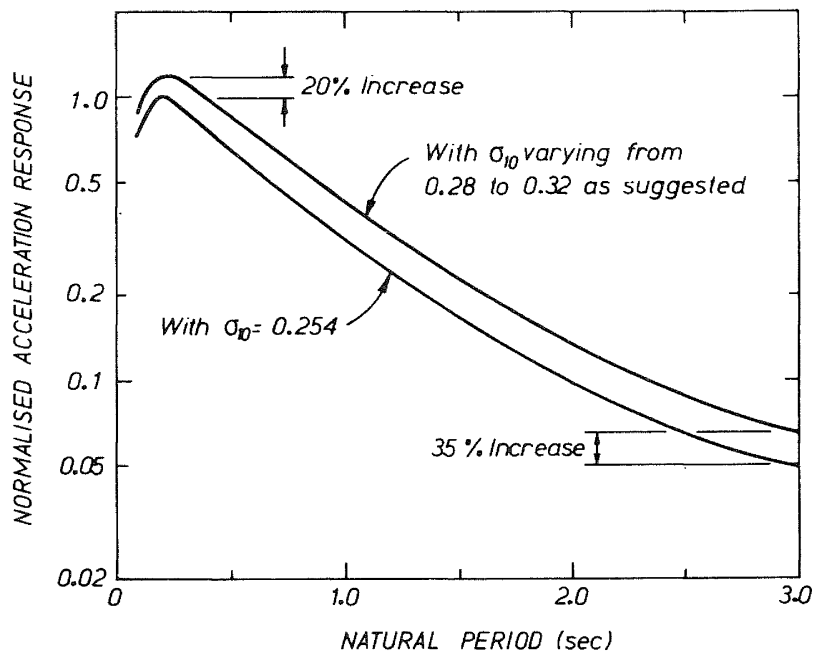

Figure 9. Comparison of uniform risk acceleration response spectra with $\sigma 10=0.254$ (from New Zealand data alone) and $\sigma 10$ as
recommended in this article. The spectra are computed for five percent critical damping, a return period a magnitude cutoff of $M=5.0$ and ground condition 3 at wellington. 


\section{SUMMARY AND CONCLUSIONS}

Uncertainty in the attenuation law makes one of the main contributions to overall uncertainty in seismic hazard analyses, and it is important that it is allowed for in hazard computations.

The origins of attenuation uncertainty have, been discussed in a companion paperlo. In the present article, a set of 22 New Zealand strong motion accelerograms has been studied in an attempt to determine an appropriate distribution of scatter for use in correcting for attenuation uncertainty in hazard analyses for New Zealand. The following conclusions are drawn:

(1) It is found to a high level of confidence, that the residuals about the widely-used attenuation expression of Katayama, Iwasaki and Seaki are lognormally distributed. This conclusion should hold for New Zealand strong motion as a whole, despite the incompleteness of the New Zealand data set;

(2) The data set is not adequate to yield reliable estimates of the standard deviation of the logarithmic residuals at distinct natural periods. Lumping the data at the nine sampling periods in the band of 0.1 to $2.0 \mathrm{~s}$ yields the apparently reliable value of $\sigma_{10}=0.254$.

However, it is noted that the data set comprises only two earthquakes larger than $M=6(M=7$ and $M=6.2)$ and from these only one recording was obtained at an epicentral distance of less than $60 \mathrm{~km}$. Thus the set is quite deficient in large earthquakes recorded at small distances. In fact, none of the recorded earthquakes caused much damage. Thus the value of $\sigma$ o $=0.254$ is not necessarily representative of damaging New Zealand earthquakes. Comparison of the New Zealand results with those from more complete data sets recorded elsewhere confirms that the value of 0.254 should be used only with extreme caution.

(3) It is proposed, in the absence of a sufficiently complete set of New Zealand accelerograms, that the New Zealand data be combined with the Japanese data of Katayama et al. for estimating scatter or uncertainty parameters. The tectonic and geologic similarity of the two countries is advanced to justify this approach. The combined data set yields values of $\sigma$ somewhat larger than 0.254 for the New Zealand data alone. It is suggested that the following values, taken from Figure 8 , be employed until sufficient New Zealand data becomes available:

\begin{tabular}{c|cccccc} 
Period & 0.10 & 0.20 & 0.30 & 0.5 & 0.7 & $\geq 1.0 \mathrm{~s}$ \\
\hline$\sigma_{10}$ & 0.280 & 0.290 & 0.30 & 0.31 & 0.315 & 0.320
\end{tabular}

It is seen from Figure 9, that for typical conditions at a wellington site, adopting these values increases the peak of the design spectrum by about 20 percent.

Finally, from the mean values of the New Zealand residuals it is seen that on the average, the Katayama, Iwasaki and Seaki attenuation expression moderately underestimates the short period spectral ordinates of the data set, by a maximum of 22 percent at $\mathrm{T}=0.3 \mathrm{~s}$, and overestimates the long period ordinates. In view of the uncertainty of the results at distinct natural periods and since the data set is lacking in long-period-rich large earthquakes, it would be imprudent to modify the attenuation model at long periods. As for the short period components, to be consistent with the proposal made above for estimating $\sigma$, any modification should be based on mean values calculated from the combined New Zealand-Japanese data set. Since the mean Japanese residuals are zero and the Japanese data comprises 277 components compared with 44 for the New Zealand set, the resulting mean residuals would be small (less than three percent under estimation). Thus for practical purposes, $\mu=0$ may be employed.

\section{ACKNOWLEDGEMENTS}

The writer wishes to acknowledge the assistance of Messrs D. Whittaker and D.B.M. Smith in computing response spectral ordinates, the Engineering Seismology section of the New zealand DSIR in making digitized strong motion accelerograms available and personnel of the New Zealand Ministry of Works, New Zealand Geological Survey and Wellington City Council in assisting with the classification of site ground conditions. The generosity of Drs. Katayama, Iwasaki and seaki in making available their residual data for Dr. Mitchel1's study is also gratefully acknowedged. Dr. R.O. Davis, Prof. J.J. Deeley and Prof. P.C. Jennings read the manuscript and made many helpful suggestions.

\section{REFERENCES}

(1) Matuschka, T. (1980). "Assessment of Seismic Hazards in New Zealand." Dept. of Civ. Eng. Res. Report No. 222. Univ. of Auckland.

(2) Peek, R. (1980). "Estimation of Seismic Risk for New Zealand." Dept. of Civ. Eng. Res. Report 80-21. Univ. of Canterbury.

(3) Mulholland, W.M. (1982). "Estimation of Design Earthquake Motion for New Zealand." Dept. of Civ. Eng. Res. Report 82-9. Univ. of Canterbury.

(4) Mulholland, W.M. (1983). "Estimation of Design Earthquake Motions for New Zealand." Proc. 3rd South Pacific Conf. Earthq. Eng. Wellington, $20-35$. 
(5) Berrill, J.B., Priestley, M.J.N. and Chapman, H.E. (1980). "Design Earthquake Loading and Ductility Demand." Earthq. Eng. Bull. N.Z. Nat. Soc.

(6) Berrill, J.B., Priestley, M.J.N. and Peek, R. (1981). "Further comments on Seismic Design Loads for Bridges." Bull. N.Z. Nat. Soc. Earthq. Eng.

(7) McGuire, R.K. (1974). "Seismic Structural Response Risk Analysis, Incorporating Peak Responses, Regressions on Earthquake Magnitude and Distance." Dept. of Civ. Eng. Res. Report R 74-5I. MIT.

(8) Der Kiureghian, A. (1977) . "Uncertainty Analysis in Seismic Rick Evaluation." ProC. 2nd ASCE Eng. Mech. Div. Specialty Conf. Raleigh N.C. $320-323$.

(9) Bender, B. (1984). "Incorporating Acceleration Variability into Seismic Hazard Analysis." Bull. Seismol. Soc. Am 74: 1451-1462.

(10) Berrill, J.B. (1985). "Seismic Hazard and Design Loads." Bull. N.Z. Nat. Soc. Earthq. Eng. $18: 1 \overline{39-150 .}$

(11) Katayama, T., Iwasaki, T. and Seaki, M. (1978). "Statistical Analysis of Earthquake Acceleration Response Spectra." Trans. Japanese Soc. Civil Eng 10: 311-313.

(12) Ohashi, M., Kuribayashi, E., Iwasaki, T. and Kawashima, K. (1979). "An Overview of the state of Practice in Earthquake Resistant Design of Highway Bridges in Japan." Proc. Workshop on Research Needs of Seismic Problems Related to Bridges. San Diego, California.

(13) Specification for Earthquake

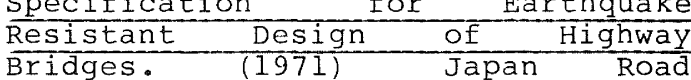
Association.

(14) Hoel, P.G. (1971). Introduction to Mathematical statistics.Wiley.

(15) Ang, A.H.S. and Tang, W.H. Probability concepts in Engineering Planning and Design. Wiley. New York.

(16) Trifinac, M.D. and Anderson, J.G. (1977). "Preliminary Empirical Models for Sealing Absolute Acceleration spectra." Report CE 77-03. Univ. of Southern Calif.

(17) Mitchell, P.H. (1981). "The Distribution of Observed Earthquake Attenuation about the Model Proposed by Katayama et al. Unpublished Report. Univ. of Canterbury.

(18) Meddis, R. (1975). Statisitcal Handbook for Non-Statisticians. MCGraw-Hill (U.K.).
(19) McVerry, G.H. (1985). "Uncertainties in Attenuation Relations for New Zealand Seismic Hazard Analyses." Paper presented at the annual conference of the Institute of Professional Engineers New Zealand. Wellington. 